\title{
Cyclopropenes as Potential Warheads for Inhibitors of Cysteine Proteases
}

\author{
Purujit N. Gurjar, Aron P. Bercz, Thi N. Nguyen, Anish K. Vadukoot, Vladislav A. Litosh* \\ Department of Chemistry, University of Cincinnati, USA
}

Copyright $@ 2015$ Horizon Research Publishing All rights reserved.

\begin{abstract}
Over expression of cysteine proteases in human body causes neurodegenerative diseases, destruction of cartilage tissue, and bone atrophy, and some of them are implicated in destructive role of malignant tumors and cancer metastasis. Several non-human cysteine proteases play a key role in life cycles of certain foreign invasive organisms. Therefore, inhibition of cysteine proteases represents an important venue for finding potential therapeutic agents against Alzheimer's disease, multiple sclerosis, ischemic stroke, myocardial infarcts, carcinoma progression, as well as some parasital and viral infections. Affinity labeling agents used as inhibitors of cysteine proteases normally bear an electrophilic "warhead", a reactive group that covalently binds the active site cysteine residue thereby inactivating the enzyme, but achieving both high activity and selectivity remains challenging. We are developing cyclopropene derivatives that show selective binding of thiol residues of cysteine. Several derivatives of cyclopropenes have been synthesized and evaluated as potential cysteine-binding "warheads". Their stability in aqueous media and reactivity toward cysteine and other amino acid chemical probes was examined. We have found that 1,2-cyclopropene moiety irreversibly binds the thiol group of cysteine, leaving other amino acid residues unaffected, which has the advantage for targeting enzymes expressed in foreign organisms or promoting carcinoma progression.
\end{abstract}

Keywords Cyclopropene, Cysteine, Thiol, Affinity Labeling

\section{Introduction}

Cysteine proteases are protein processing and protein degrading enzymes whose overexpression in human body may result in serious pathological changes. For instance, calpains, one type of cysteine proteases, are involved in Alzheimer disease, multiple sclerosis, stroke, myocardial infarcts, cataract formation, etc. ${ }^{1}$ Destruction of cartilage tissue and bone atrophy is the result of over expressed cathepsins, ${ }^{2}$ which are also involved in carcinoma progression and metastasis. ${ }^{3}$ Other cysteine proteases play an essential role in life cycles of some viruses (e.g., coronavirus $^{4}$ ) and parasites (e.g., malaria ${ }^{5}$ ). Therefore, developing inhibitors of cysteine proteases is an important target for organic and medicinal chemists.

The most efficient inhibitors of cysteine proteases bear an electrophilic "warhead" capable of covalently binding active site cysteine residues. Examples include species containing activated carbon-carbon double bonds, ${ }^{6}$ acyloxymethyl ketones, ${ }^{7}$ and a three-membered ring heterocycles (e.g., epoxide, ${ }^{8}$ aziridine $\left.{ }^{9}\right)$, the latter generally having greater potency. $^{9-10}$ Their activity, however, is strongly $\mathrm{pH}$ dependent, and the inhibition is not always restricted to cysteine proteases, often affecting aspartate and serine proteases as well. ${ }^{10 a}$ Surprisingly, among carbocyclic unsaturated three-membered ring compounds, only cyclopropenone derivatives have been used as cysteine protease inhibitors, ${ }^{11}$ and their binding appears to be reversible (Figure 1). ${ }^{11 \mathrm{~b}}$ This suggests the addition of the cysteine thiol group to the 3-carbonyl, rather than to the cyclopropene double bond. To the contrary, 1,2-cyclopropene moiety irreversibly inhibits acyl desaturases, other enzymes where cysteine residue plays the catalytic role, by reaction with the cysteine residue of the active site, leaving other amino acid chemical probes unaffected. $^{12}$ It can, therefore, be hypothesized that inhibitors bearing a cyclopropene "warhead" will provide excellent drug candidates that will inhibit cysteine proteases selectively and irreversibly, which is particularly advantageous for targeting enzymes expressed in foreign organisms (e.g. falcipains in malaria parasite or C3-like protease in coronavirus) or those that are over expressed in neoplastic tissues (e.g. cathepsins L, B, H, and S).

In this paper, we report the synthesis of model cyclopropenes and their evaluation as potential warheads that could be incorporated into the existing cysteine protease inhibitors in order to increase their selectivity and potency. 


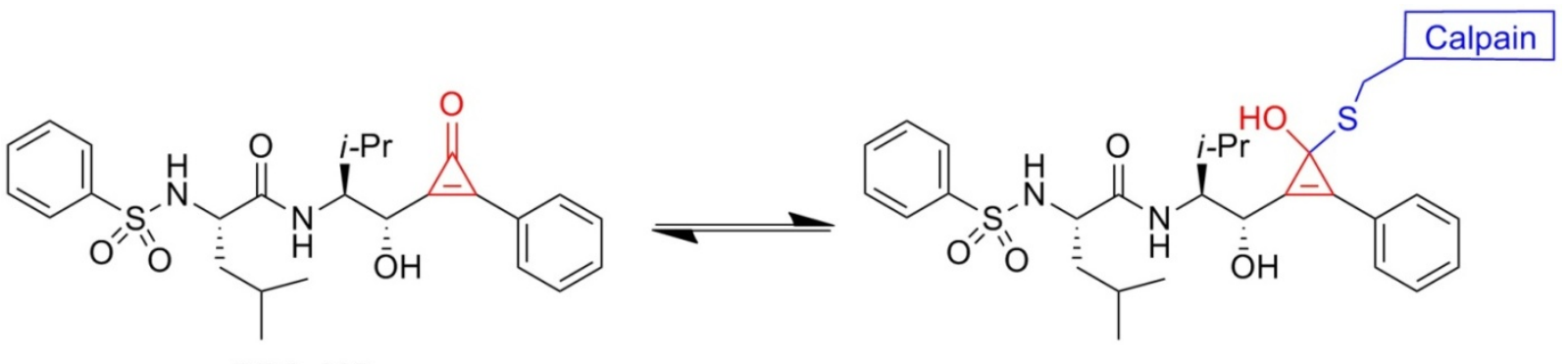

Figure 1. Cysteine protease inhibitor containing a cyclopropenone warhead and its mechanism of action.

\section{Results and Discussion}

There are three main routes ${ }^{13}$ to access cyclopropenes by synthesis: 1,2-elimination of cyclopropanes, cyclization of vinylcarbenes, and addition of carbenes to carbon-carbon triple bonds. The latter method represents, perhaps, the most plausible way to synthesize cyclopropenes, as it constructs the three membered ring by simultaneous formation of the two sigma bonds. Most importantly, it is not limited to free carbenes; metallocarbenoids also readily undergo reaction with alkynes, with dirhodium(II) catalyst being the most efficient for cyclopropenation of terminal alkynes using the corresponding diazo compounds ${ }^{14}$ to form the cyclopropene with the desired C3-substitution pattern. This method, however, does not work well for halocarbenes, as their metallocarbenoids react differently with terminal alkynes, ${ }^{15}$ so 3,3-difluorocyclopropenes were synthesized by addition of the difluorocarbene, generated in situ, ${ }^{16}$ to the alkynes (Scheme 1). Furthermore, 1-(trimethylsilyl)cyclopropene ${ }^{17}$ can be easily converted into 1,2-non-substituted cyclopropenes by hydrolysis in mild basic conditions.

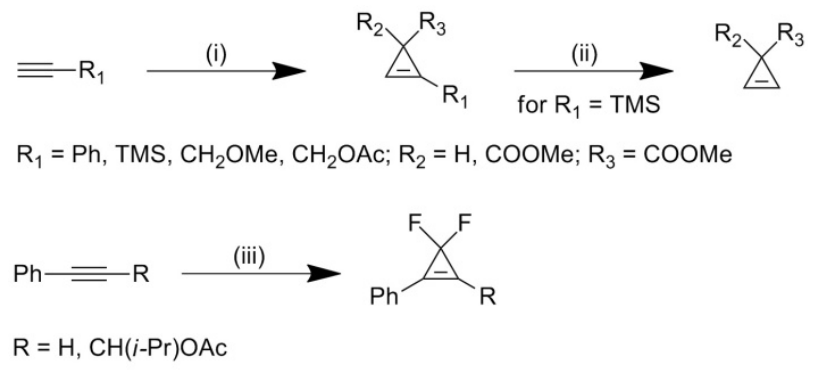

Scheme 1. Synthesis of cyclopropenes by carbene addition to a triple bond. (i) $\mathrm{R}_{2} \mathrm{R}_{3} \mathrm{C}=\mathrm{N}_{2}, \mathrm{Rh}_{2}(\mathrm{OAc})_{4}, \mathrm{CH}_{2} \mathrm{Cl}_{2}$, r.t.; (ii) $\mathrm{K}_{2} \mathrm{CO}_{3}$, $\mathrm{THF} / \mathrm{H}_{2} \mathrm{O}$, r.t.; (iii) $\mathrm{TMSCF}_{3}, \mathrm{NaI}, 110^{\circ} \mathrm{C}, 2 \mathrm{~h}$.

Our initial stability studies revealed that 3-monosubstituted cyclopropenes $\left(\mathrm{R}_{2}=\mathrm{H}\right)$ and 1-phenyl-3, 3 -difluorocyclopropene were not stable for an extended period of time, even in $\mathrm{CDCl}_{3}$. The other halogenated analog, 1-phenyl-2-(1-acetoxy-2-methyl)propyl-3,3-difluorocyclopr opene, albeit stable at room temperature in an aprotic solvent, rapidly decomposed upon the contact with a phosphate aqueous buffer ( $\mathrm{pH}$ 7.4). Other cyclopropene derivatives turned out to be sufficiently stable toward hydrolysis, so we proceeded with studies of their reactivity toward $\mathrm{N}$-acetyl cysteine methyl ester.

We, therefore, measured the pseudo-first-order reaction rates for each of the 3,3-dicarboxymethylcyclopropenes with $\mathrm{N}$-acetylcysteine methyl ester using ${ }^{1} \mathrm{H}$ NMR spectroscopy in $\mathrm{CD}_{3} \mathrm{CN}$ in the presence of 1,8-diazabicyclo[5.4.0] undec-7-ene (DBU) needed to ionize the SH (without any base no reaction is observed) at $37{ }^{\circ} \mathrm{C}$. The reaction progress was monitored by disappearance of the cyclopropene hydrogen signal in ${ }^{1} \mathrm{H}$ NMR (Figure 2). We found that the fastest reacting cyclopropene was the 1-phenyl derivative, while 1-alkyl substituted cyclopropenes reacted the slowest, displaying more than 459-826 fold difference (Table 1). This is consistent with the stabilization effect of 1 -aryl group on the intermediate carbanion whose formation is commonly proposed (Scheme 2). Surprisingly, however, the reactivity of 1-trimethysilyl-3,3-dicarboxymethylcyclop ropene was somewhat lower, matching closely that of the parent 3, 3-dicarboxymethylcyclopropene, but still substantially higher than that of the 3-alkyl derivatives.

Table 1. Pseudo first order reaction rates

\begin{tabular}{cc}
\hline $\mathrm{R}$ & $\mathrm{k}\left(\mathrm{s}^{-1}\right)$ \\
\hline Phenyl & $1.1 \times 10^{-2}$ \\
$\mathrm{H}$ & $4.3 \times 10^{-2}$ \\
$\mathrm{TMS}$ & $4.2 \times 10^{-2}$ \\
$\mathrm{CH}_{2} \mathrm{OMe}$ & $9 \times 10^{-4}$ \\
$\mathrm{CH}_{2} \mathrm{OAc}$ & $5 \times 10^{-4}$ \\
\hline
\end{tabular}



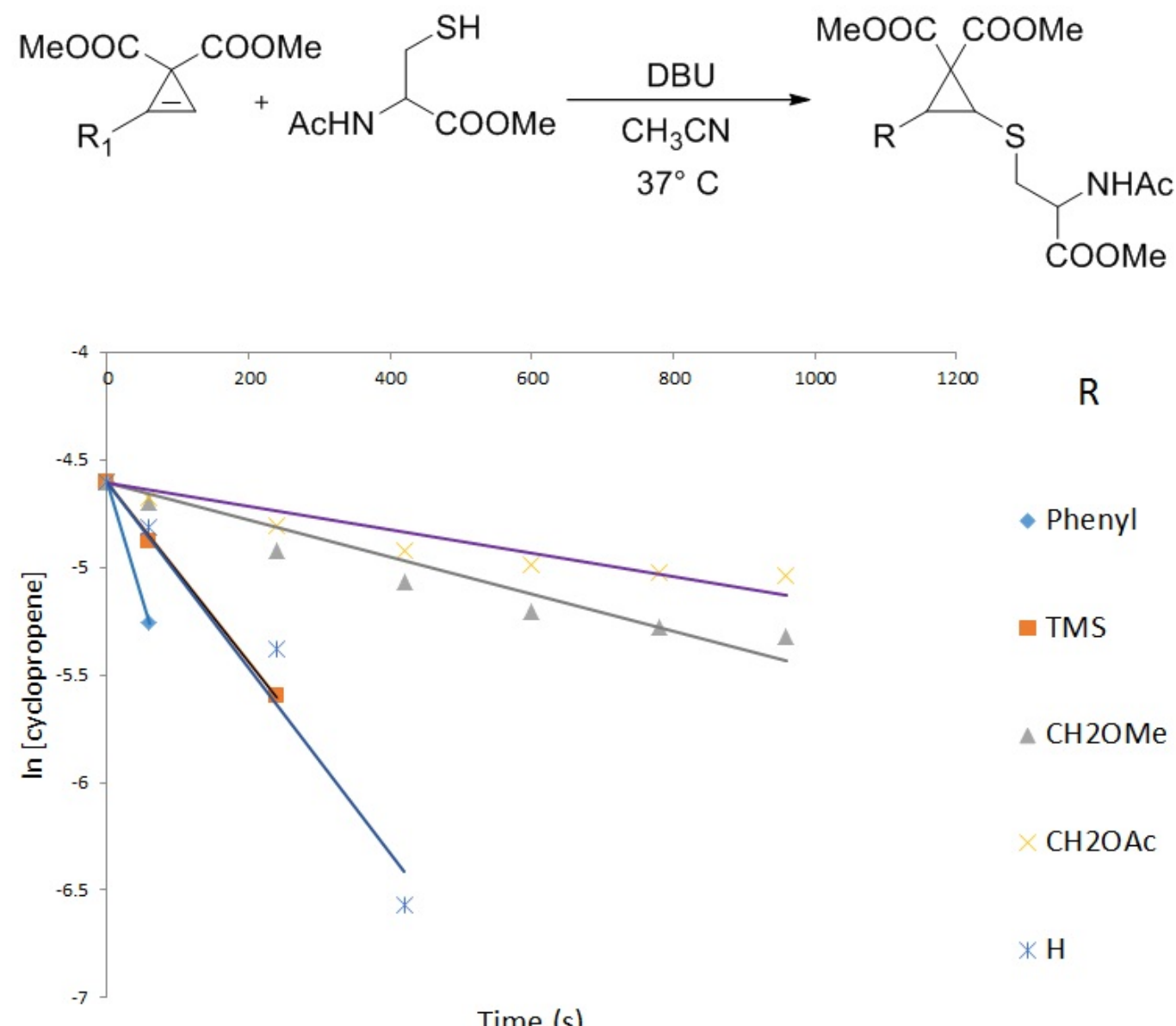

Figure 2. ${ }^{1} \mathrm{H}$ NMR studies to determine reaction rate for addition of cyclopropene derivatives to methyl $N$-acetylcysteinate

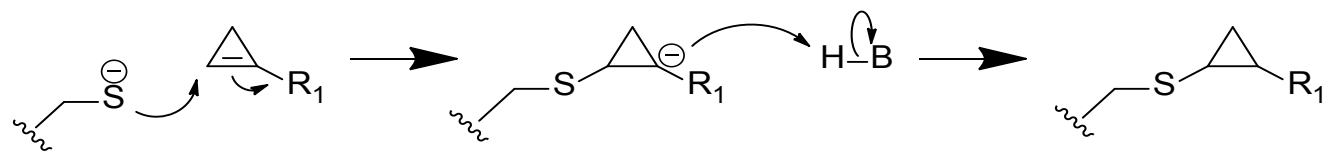

Scheme 2. Proposed mechanism of the thiol addition to cyclopropene

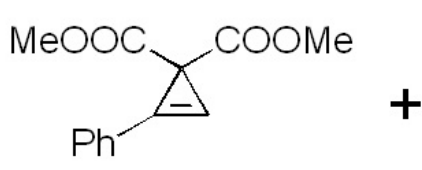<smiles>CCN[C@@H](CS)C(C)=O</smiles>

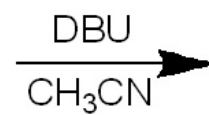

$37^{\circ} \mathrm{C}$

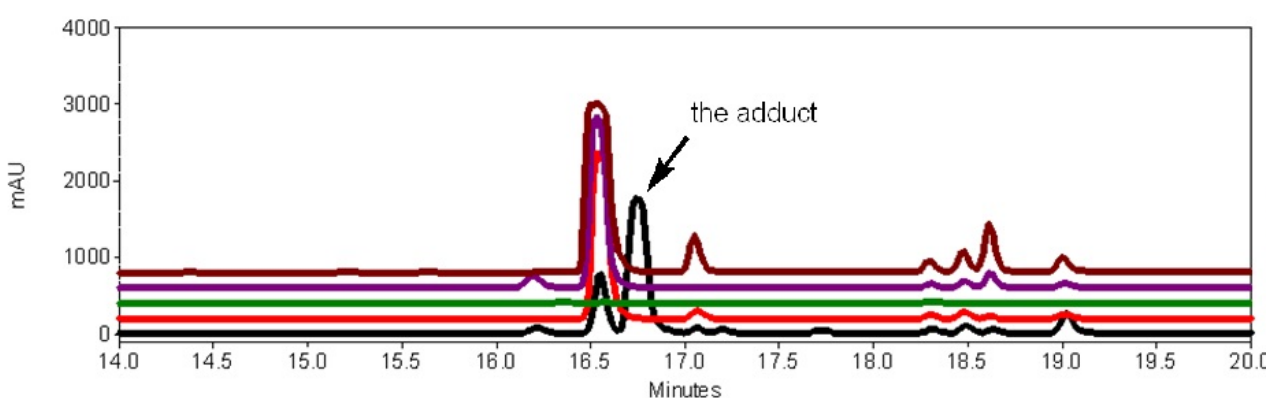

Figure 3. HPLC profile of the reaction of 1-phenyl-3,3-dicarboxymethylcyclopropene with methyl $N$-acetylcysteinate<smiles></smiles>

- Cyclopropene only

- Cysteine derivarive $+\mathrm{DBU}$

- Cyclopropene + Cysteine derivative

- Cyclopropene + Cysteine derivative + DBU 


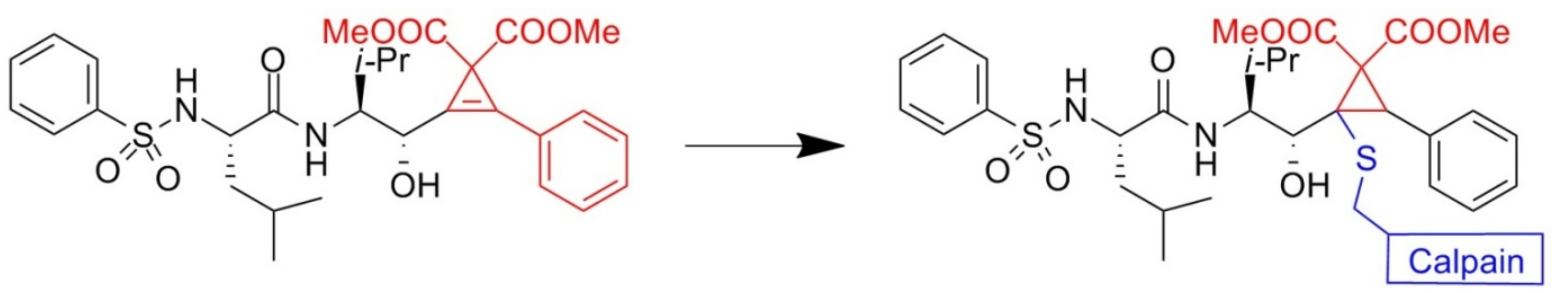

Figure 4. Proposed novel irreversible cysteine protease inhibitor with a cyclopropene warhead

The reaction of 1-phenyl-3,3-dicarboxy-methylcycloprop ene with methyl $\mathrm{N}$-acetylcysteinate, was profiled using HPLC with UV detection (Figure 3). The addition product was isolated as a diasteromeric mixture and identified by NMR and HRMS spectroscopy. There was no reaction between either cyclopropene derivative in Table $\mathbf{1}$ with similarly derivatized serine and aspartic acid.

Thus, 1-phenyl-3,3-dicarboxymethyl-cyclopropene appears to be the warhead of choice for the contemplated synthesis of the proposed irreversible inhibitor analogous to BDA-410 (Figure 4), as it is most reactive toward cysteine among all the reasonably stable cyclopropene derivatives identified in these studies.

\section{Conclusions}

We have determined that 1,3,3-trisubstituted cyclopropenes are sufficiently stable, reactive, and selective toward cysteine residues. Attachment of a phenyl substituent at C-1 capable of stabilizing an intermediate carbanion enhances the reactivity of the cyclopropene moiety toward cysteine residue, thereby making 1-phenylcyclopropenes promising warheads for potential cysteine protease inhibitors. The substitution at $\mathrm{C} 3$, however, has to be limited to carbon atoms, as 3,3-dihalo derivatives appear to be too reactive to be stable in aqueous media.

\section{Acknowledgements}

This work was supported by the University of Cincinnati start-up funds for Prof. Litosh.

\section{Experimental}

All chemicals, reagents, and solvents were purchased from Sigma-Aldrich Inc., TCI, and Fisher Scientific, Inc., and used as received. Unless stated otherwise, all reactions were carried out under an atmosphere of dry argon in oven-dried glassware. Indicated reaction temperatures refer to those of the reaction bath, while room temperature (rt) is noted as $25^{\circ} \mathrm{C}$. Analytical thin layer chromatography (TLC) was performed with glass backed silica plates $(5 \times 20 \mathrm{~cm}, 60 \AA$, $250 \mu \mathrm{m})$. Visualization was accomplished using a $254 \mathrm{~nm}$ UV lamp. ${ }^{1} \mathrm{H}$ and ${ }^{13} \mathrm{C}$ NMR spectra were recorded on either a Bruker Avance $400 \mathrm{MHz}$ spectrometer or Bruker DPX 500
$\mathrm{MHz}$ spectrophotometer using solutions of samples in either of the deturated solvents: chloroform or acetonitrile. Chemical shifts are reported in ppm with tetramethylsilane as standard. Data are reported as follows: chemical shift, number of protons, multiplicity $(\mathrm{s}=$ singlet, $\mathrm{d}=$ doublet, $\mathrm{dd}=$ doublet of doublet, $\mathrm{t}=$ triplet, $\mathrm{q}=$ quartet, $\mathrm{b}=$ broad, $\mathrm{m}=$ multiplet), and coupling constants. High resolution mass spectral data were collected on a Shimadzu Q-TOF 6500. All novel compounds were characterized by ${ }^{1} \mathrm{H},{ }^{13} \mathrm{C}$ NMR spectroscopy and high resolution mass spectrometry. Previously synthesized compounds were identified by comparison of their ${ }^{1} \mathrm{H}$ NMR to the published data (reference provided). Preparative high performance liquid chromatography (HPLC) was performed on an Agilent 1200 HPLC with UV detection.

Tosyl azide. ${ }^{18}$ To a solution of sodium azide (11.9 g, 62.5 $\mathrm{mmol})$ in the mixture of water $(15 \mathrm{~mL})$ and $95 \%$ ethanol $(25$ $\mathrm{mL}$ ) a solution of p-toluenesulfonyl chloride (4.475 g, 70 $\mathrm{mmol})$ in $95 \%$ ethanol $(125 \mathrm{~mL})$ was added. After stirring at $40{ }^{\circ} \mathrm{C}$ for 3 hours, the solvent was removed in vacuo. The oily crude product was dissolved in diethyl ether, washed with water, dried using sodium sulfate and purified with hexane/ethyl acetate (6:1) to yield $11.6 \mathrm{~g}(84 \%)$ of product. ${ }^{1} \mathrm{H} \mathrm{NMR}\left(\mathrm{CDCl}_{3}, 400 \mathrm{MHz}\right): \delta 7.83(\mathrm{~d}, J=8.0 \mathrm{~Hz}, 2 \mathrm{H}), 7.40$ (d, $J=8.0 \mathrm{~Hz}, 2 \mathrm{H}), 2.47$ (s, $3 \mathrm{H})$.

Dimethyl diazomalonate. ${ }^{19}$ Dimethylmalonate $(1.05 \mathrm{~mL}$, $1.0 \mathrm{eq})$, triethylamine $(1.4 \mathrm{~mL}, 1.1 \mathrm{eq})$ and tosyl azide $(2 \mathrm{~g}$, $1.0 \mathrm{eq})$ were dissolved in acetonitrile $(20 \mathrm{~mL})$. The solution was stirred at room temperature overnight. The reaction mixture was concentrated under reduced pressure and partitioned between $\mathrm{CH}_{2} \mathrm{Cl}_{2}$ and water. The resulting solution was stirred for 1 hour at room temperature. The organic layer was collected, dried over anhydrous $\mathrm{MgSO}_{4}$ and concentrated. Crude mixture was first filtered over a plug of silica gel (Pet ether/diethyl ether 1:1) to remove most of the tosylamide. The purification by silica gel chromatography with Pet ether/diethyl ether 1:1 afforded product as a yellow oil. ${ }^{l} \mathrm{H} \mathrm{NMR}\left(\mathrm{CDCl}_{3}, 400 \mathrm{MHz}\right): \delta 3.84$ (s, $6 \mathrm{H})$.

General procedure for rhodium acetate mediated cyclopropenation. ${ }^{20}$ To a solution of an appropriate alkyne (3.0 eq) and $\mathrm{Rh}_{2}(\mathrm{OAc})_{4}(0.01 \mathrm{eq})$ in anhydrous $\mathrm{CH}_{2} \mathrm{Cl}_{2}$ solution of dimethyl diazomalonate (1.0 eq) in anhydrous $\mathrm{CH}_{2} \mathrm{Cl}_{2}$ was added dropwise using an automated syringe pump with the rate of $0.7 \mathrm{~mL} /$ hour at room temperature. After the completion of addition, reaction was stirred for additional 3 hours followed by filtration through a plug of 
celite and purification using silica gel chromatography with hexane-ethyl acetate eluent system.

1-phenyl-3,3-dicarboxymethylcyclopropene. ${ }^{20}$ (Yield: $81 \%)^{l} \mathrm{H} \mathrm{NMR}\left(\mathrm{CDCl}_{3}, 400 \mathrm{MHz}\right): \delta 7.64(\mathrm{~m}, 2 \mathrm{H}), 7.45(\mathrm{~m}$, $3 \mathrm{H}), 6.90$ (s, $1 \mathrm{H}), 3.72(\mathrm{~s}, 6 \mathrm{H})$

1-trimethylsilyl-3,3-dicarboxymethylcyclopropene. ${ }^{17}$ (Yield: 92\%) ${ }^{1} \mathrm{H} \mathrm{NMR}\left(\mathrm{CDCl}_{3}, 400 \mathrm{MHz}\right): \delta 7.04(\mathrm{~s}, 1 \mathrm{H})$, $3.69(\mathrm{~s}, 6 \mathrm{H}), 0.24(\mathrm{~s}, 9 \mathrm{H})$

1-(acetoxy)methyl-3,3-dicarboxymethylcyclopropene. ${ }^{2}$ ${ }^{1}$ (Yield: 47\%) ${ }^{l} \mathrm{H} \mathrm{NMR}\left(\mathrm{CDCl}_{3}, 400 \mathrm{MHz}\right): \delta 6.71(\mathrm{~s}, 1 \mathrm{H})$, 5.08 (s, $2 \mathrm{H}), 3.73$ (s, $6 \mathrm{H}), 2.11(\mathrm{~s}, 3 \mathrm{H})$

1-(methoxy)methyl-3,3-dicarboxymethylcyclopropene. ${ }^{21}$ (Yield: $\left.10 \%\right){ }^{l} H \mathrm{NMR}\left(\mathrm{CDCl}_{3}, 400 \mathrm{MHz}\right): \delta 6.64(\mathrm{t}, J=$ $1.6 \mathrm{~Hz}, 1 \mathrm{H}), 4.43(\mathrm{~d}, J=1.6 \mathrm{~Hz}, 2 \mathrm{H}), 3.66(\mathrm{~s}, 6 \mathrm{H}), 3.36$ (s, $3 \mathrm{H})$

General procedure for TMS deprotection. 1-(trimethyl)silyl-3,3-disubstituted cyclopropene (1 g) was dissolved in $20 \mathrm{~mL}$ of regular THF. The resulting solution was cooled at $0{ }^{\circ} \mathrm{C}$ and $10 \%$ aq. $\mathrm{K}_{2} \mathrm{CO}_{3}$ was added dropwise. Upon completion of the addition, the reaction mixture was stirred for another $10 \mathrm{~min}$ at $0{ }^{\circ} \mathrm{C}$, then for 24 hours while gradually warming up to room temperature. The solvent was removed under reduced pressure and crude mixture was purified using silica gel chromatography with hexane-ethyl acetate system.

3,3-dicarboxymethylcyclopropene. ${ }^{22}$ (Yield: 95\%) ${ }^{1} \mathrm{H}$ NMR (CDCl, $400 \mathrm{MHz}): \delta 6.89(\mathrm{~s}, 2 \mathrm{H}), 3.70(\mathrm{~s}, 6 \mathrm{H})$.

General procedure for difluorocarbene addition to a carbon-carbon triple bond. ${ }^{16}$ Appropriate alkyne (1 eq), anhydrous $\mathrm{NaI}$ (2.2 eq), $\mathrm{TMSCF}_{3}$ (2 eq) were dissolved in anhydrous THF. The reaction mixture was heated overnight at $110{ }^{\circ} \mathrm{C}$ in a high pressure sealed tube. Upon cooling down, the mixture was quenched with saturated $\mathrm{Na}_{2} \mathrm{CO}_{3}$ solution, followed by extraction with diethyl ether. The organic phase was dried over anhydrous $\mathrm{K}_{2} \mathrm{CO}_{3}$. The solvent was removed under reduced pressure, and the residue was purified using silica gel chromatography with petroleum ether / triethylamine $(40: 1, \mathrm{v} / \mathrm{v})$ as eluent.

1-phenyl-3,3-difluorocyclopropene. ${ }^{15}$ This compound was not stable enough for subsequent studies.

1-phenyl-2-(1-acetoxy-2-methyl)propyl-3,3-difluorocy

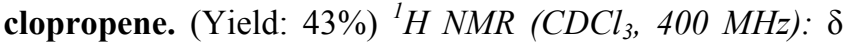
$7.63(\mathrm{~m}, 2 \mathrm{H}), 7.48(\mathrm{~m}, 3 \mathrm{H}), 5.76(\mathrm{~m}, 1 \mathrm{H}), 2.20(\mathrm{~s}, 3 \mathrm{H})$, $2.22(\mathrm{~m}, 1 \mathrm{H}), 1.08(\mathrm{~d}, 3 \mathrm{H}, J=6.9 \mathrm{~Hz}), 1.04(\mathrm{~d}, 3 \mathrm{H}, J=$ 6.8Hz). ${ }^{13} \mathrm{CNMR}\left(\mathrm{CDCl}_{3}, 400 \mathrm{MHz}\right): \delta 169.97(\mathrm{~s}), 131.23(\mathrm{~s})$, 130.34 (s), 129.10 (s), 128.57 (t, $J=10.8 \mathrm{~Hz}), 124.33$ (t, $J=$ $11.9 \mathrm{~Hz}), 123.36(\mathrm{~s}), 102.09(\mathrm{t}, J=273 \mathrm{~Hz}), 73.19$ (s), 31.62 (s), 20.93 (s), 17.83 (s), 17.48 (s).

General procedure for reaction of modified cysteine with cyclopropenes. A solution of cyclopropene (1 eq.) and methyl $\mathrm{N}$-acetylcysteinate (10 eq.) in $500 \mu \mathrm{L}$ acetonitrile- $\mathrm{D}_{3}$ was placed into the NMR tube, and DBU (2 mol\%) was added. The mixture was stirred using a vortex and NMR was taken at regular time intervals. The rate of the reaction was calculated using disappearance of the characteristic cyclopropene peak.

Methyl $\mathrm{N}$-acetyl-S-(2-phenyl-3, 3-dicarboxymethylcyclopropan-1-yl)cysteinate. The adduct between $N$-acetyl-cysteine methyl ester and 1-phenyl-3, 3-dicarboxymethylcyclopropene was isolated by preparative HPLC using reverse-phase C18 column and acetonitrile/water $=5: 95$ to $50: 50$ as a mixture of stereoisomers (Yield: $\mathrm{ca} \mathrm{15 \% ).}{ }^{\mathrm{I}} \mathrm{H} \mathrm{NMR}\left(\mathrm{CDCl}_{3}, 400 \mathrm{MHz}\right)$ : for major diastereomer $\delta 7.28(\mathrm{~m}, 3 \mathrm{H}), 7.20(\mathrm{~m}, 2 \mathrm{H}), 6.53(\mathrm{~d}$, $1 \mathrm{H}, J=6.9 \mathrm{~Hz}), 4.93(\mathrm{~m}, 1 \mathrm{H}), 3.85(\mathrm{~d}, 3 \mathrm{H}, J=11.5 \mathrm{~Hz})$, $3.78(\mathrm{~s}, 3 \mathrm{H}), 3.45(\mathrm{~d}, 3 \mathrm{H}, J=5.6 \mathrm{~Hz}), 3.32(\mathrm{t}, 1 \mathrm{H}, J=8.3$ $\mathrm{Hz}), 3.20$ (m, $1 \mathrm{H}), 3.07$ (m, $1 \mathrm{H}), 2.03$ (d, $3 \mathrm{H}, J=8.2 \mathrm{~Hz})$. ${ }^{13} \mathrm{C} \mathrm{NMR}\left(\mathrm{CDCl}_{3}, 400 \mathrm{MHz}\right)$ : for major diastereomer $\delta$ $170.85,169.95,166.17,166.17,133.22,128.69$, 128.40, 127.77, 53.16, 52.81, 52.36, 46.13, 37.02, 35.78, 32.37, 31.20, 22.99. HRMS (ESI): $\mathrm{m} / z$ calculated for $[\mathrm{M}+\mathrm{Na}]^{+}$ 432.1021, observed 432.1087

\section{Supporting Information Available}

${ }^{1} \mathrm{H},{ }^{13} \mathrm{C}$ NMR and HRMS spectra of synthesized compounds.

Supporting Information: Spectra $\left({ }^{1} \mathrm{H},{ }^{13} \mathrm{C}, \mathrm{DEPT}{ }^{13} \mathrm{C}\right.$, HRMS), HPLC profiling 
Solvent: $\mathrm{CDCl}_{3}$

PG-1-66-liquid.1.fi
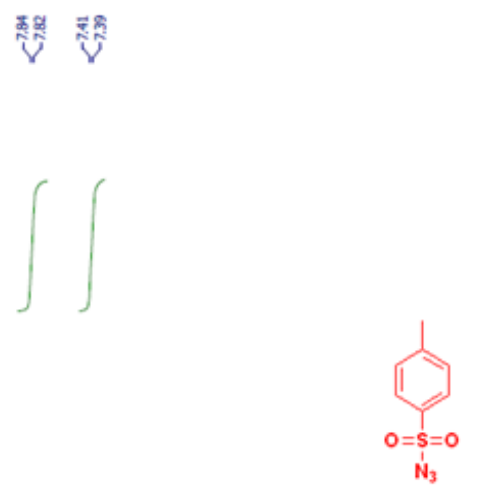

Tosyl azide

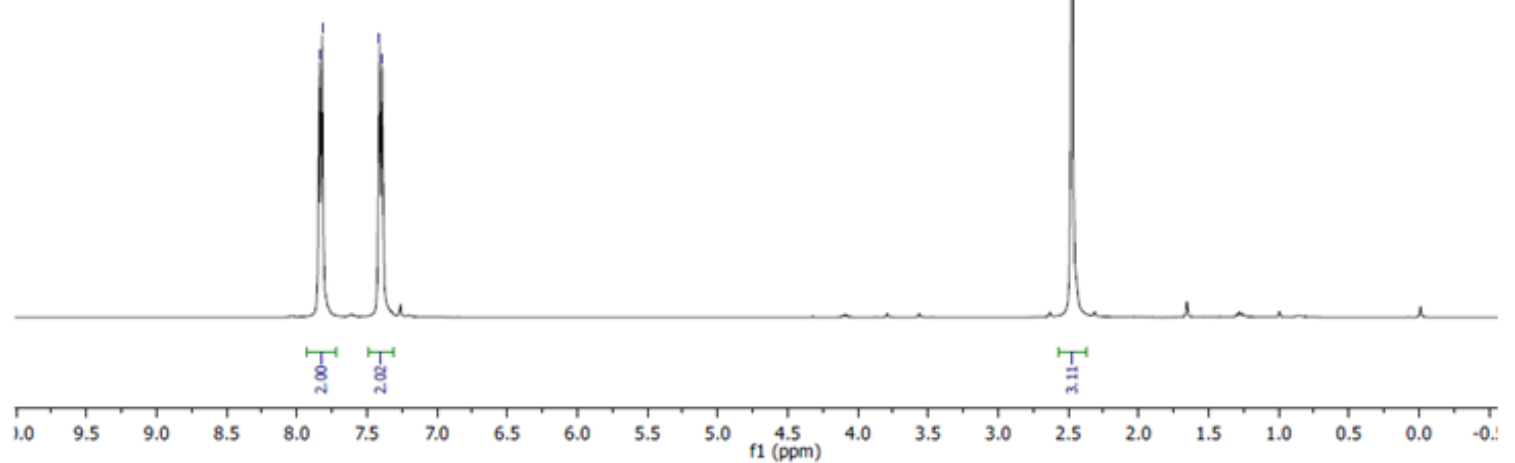

PG-1-75.1.fid สุ้

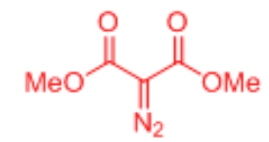

Dimethyldiazomalonate

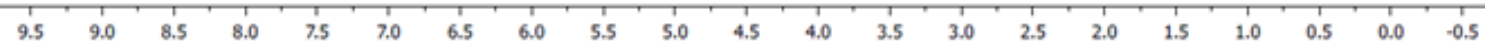


22

Cyclopropenes as Potential Warheads for Inhibitors of Cysteine Proteases

Solvent: $\mathrm{CDCl}_{3}$

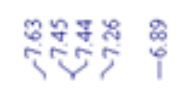

$\stackrel{8}{\stackrel{8}{1}}$ $\underset{i}{i}$ $\stackrel{1}{\frac{1}{1}} \frac{1}{1}$

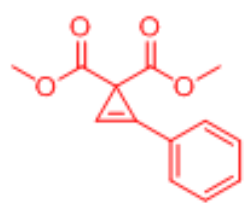

1-phenyl-3,3-dicarboxymethylcyclopropene

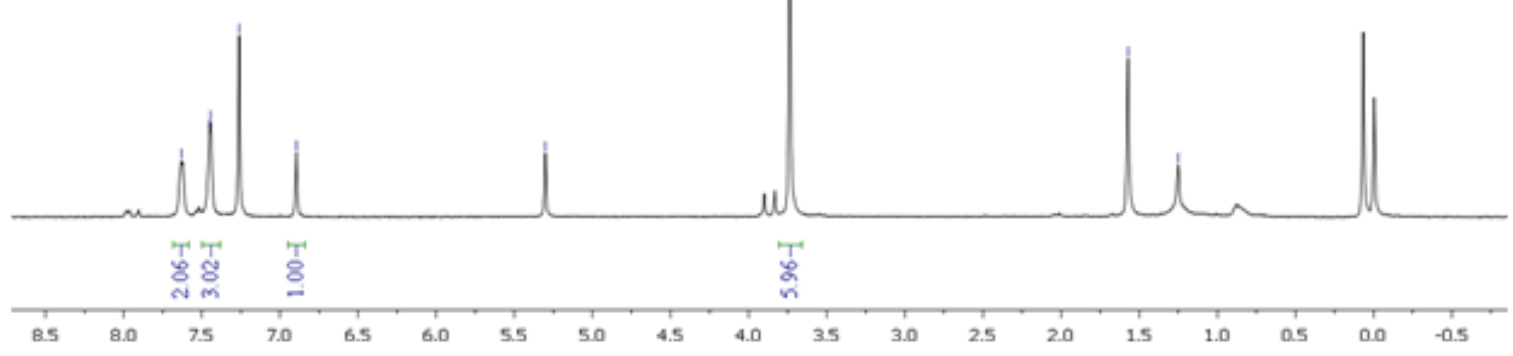

Solvent: $\mathrm{CDCl}_{3}$

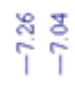

$\stackrel{8}{i}$

ii

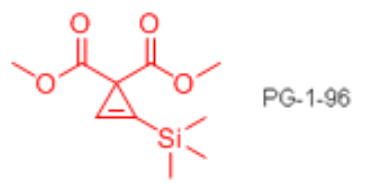

1-trimethylsilyl-3,3-dicarboxymethylcyclopropene

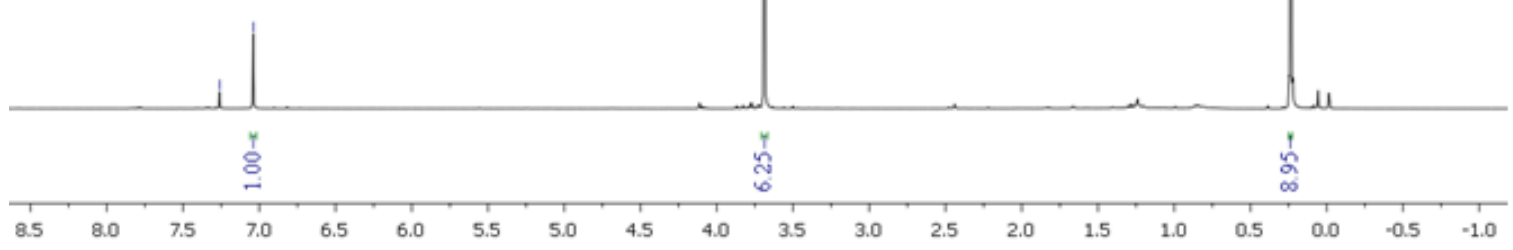


Solvent: $\mathrm{CDCl}_{3}$

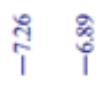

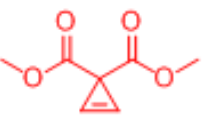

3,3-dicarboxymethylcyclopropene

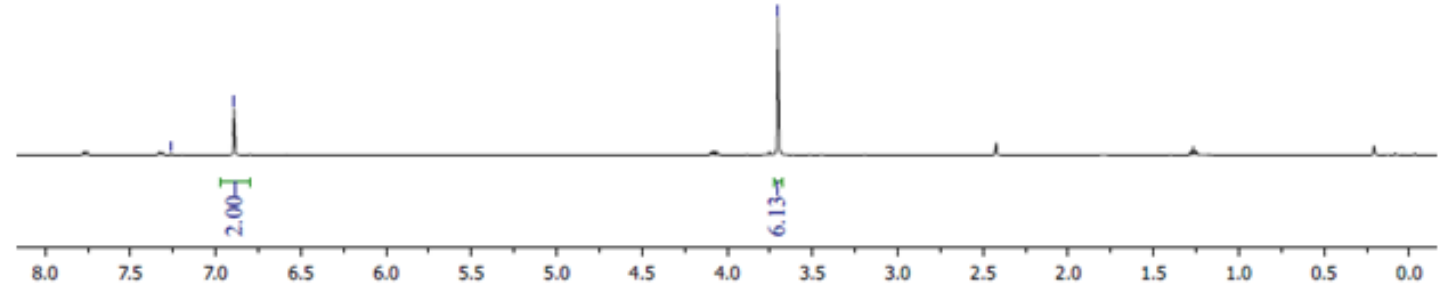

Solvent: $\mathrm{CDCl}_{3}$

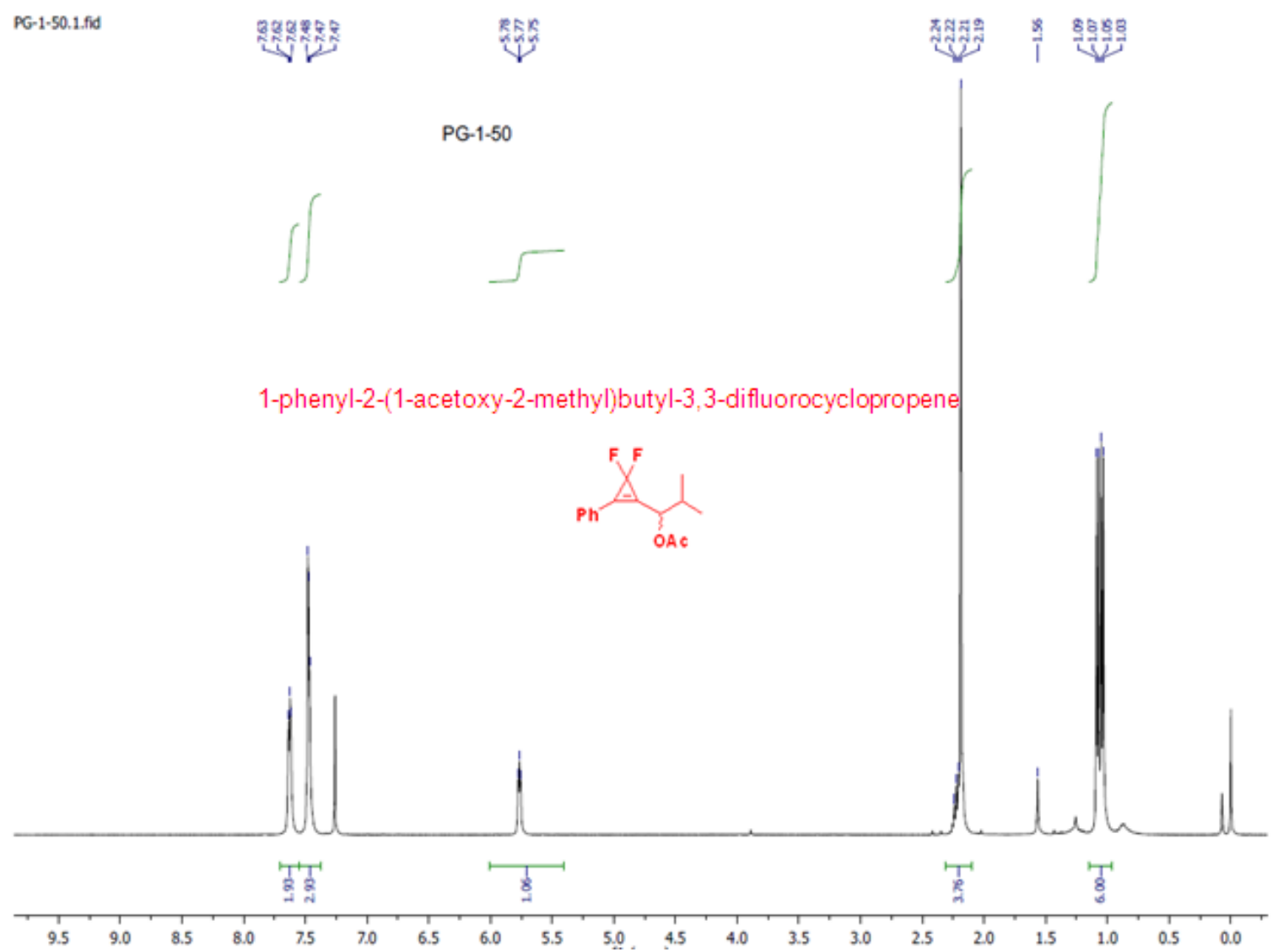


Solvent: $\mathrm{CDCl}_{3}$
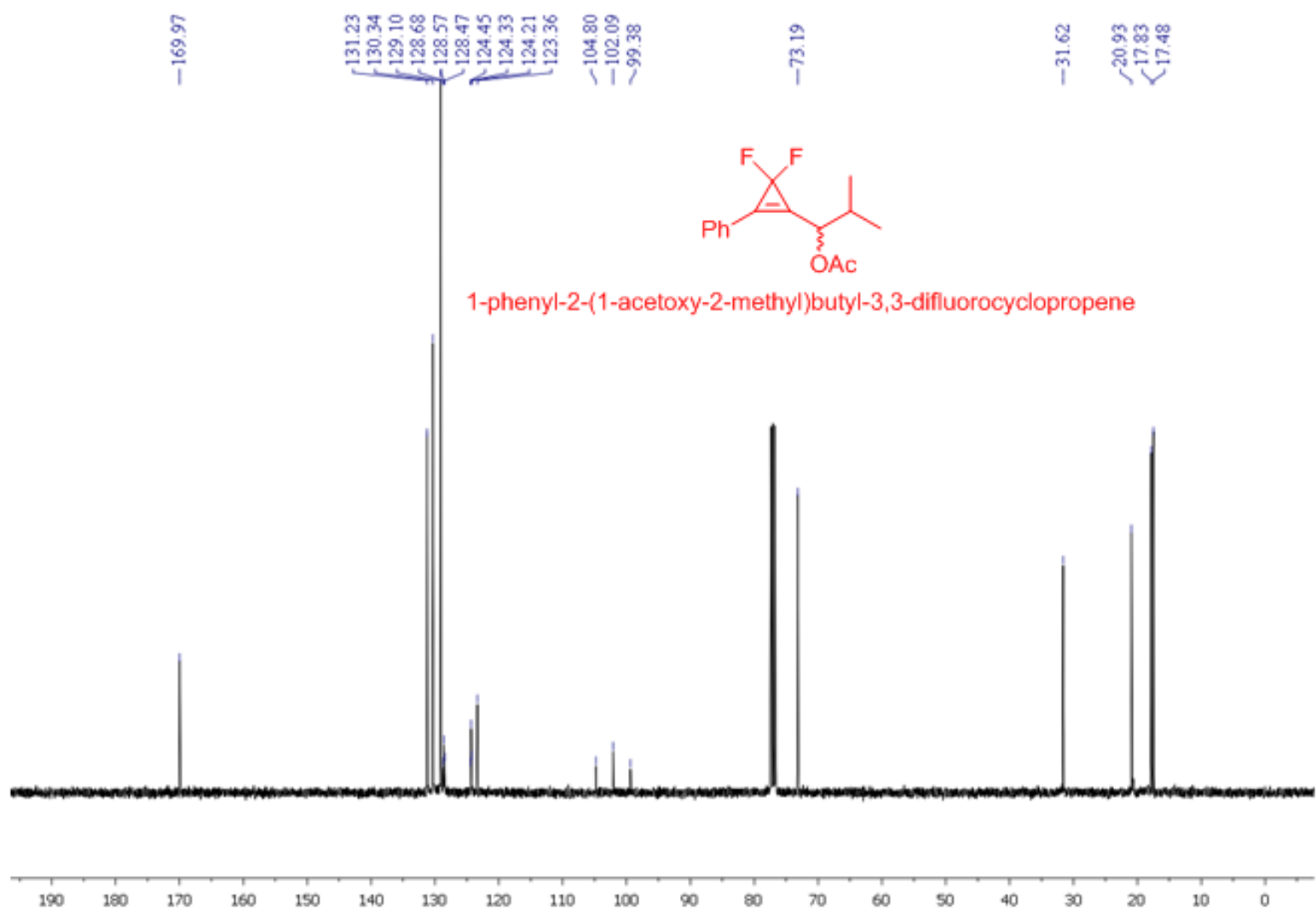

Solvent: $\mathbf{C D C l}_{3}$
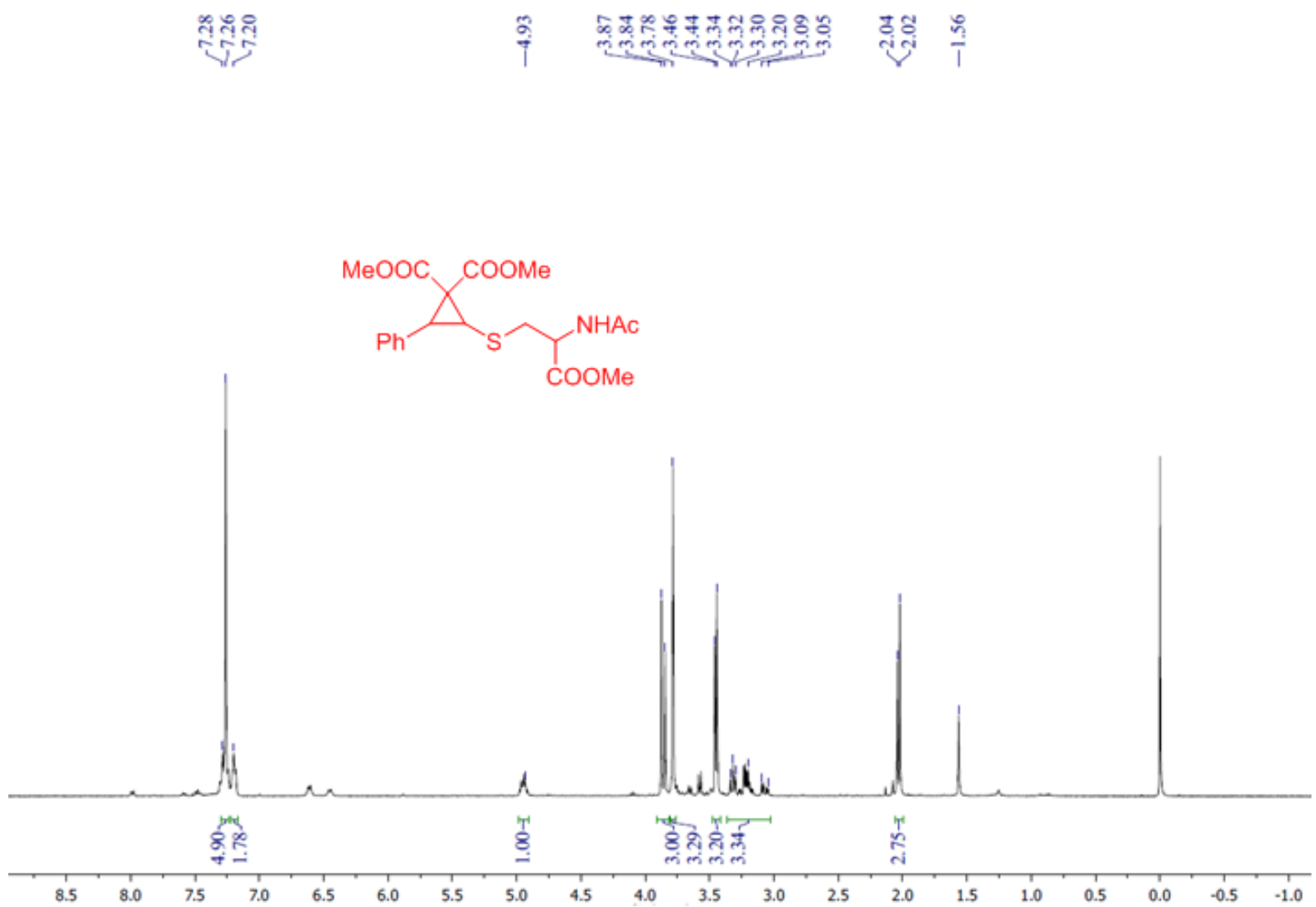
Universal Journal of Chemistry 3(1): 16-26, 2015

25

Solvent: $\mathrm{CDCl}_{3}$
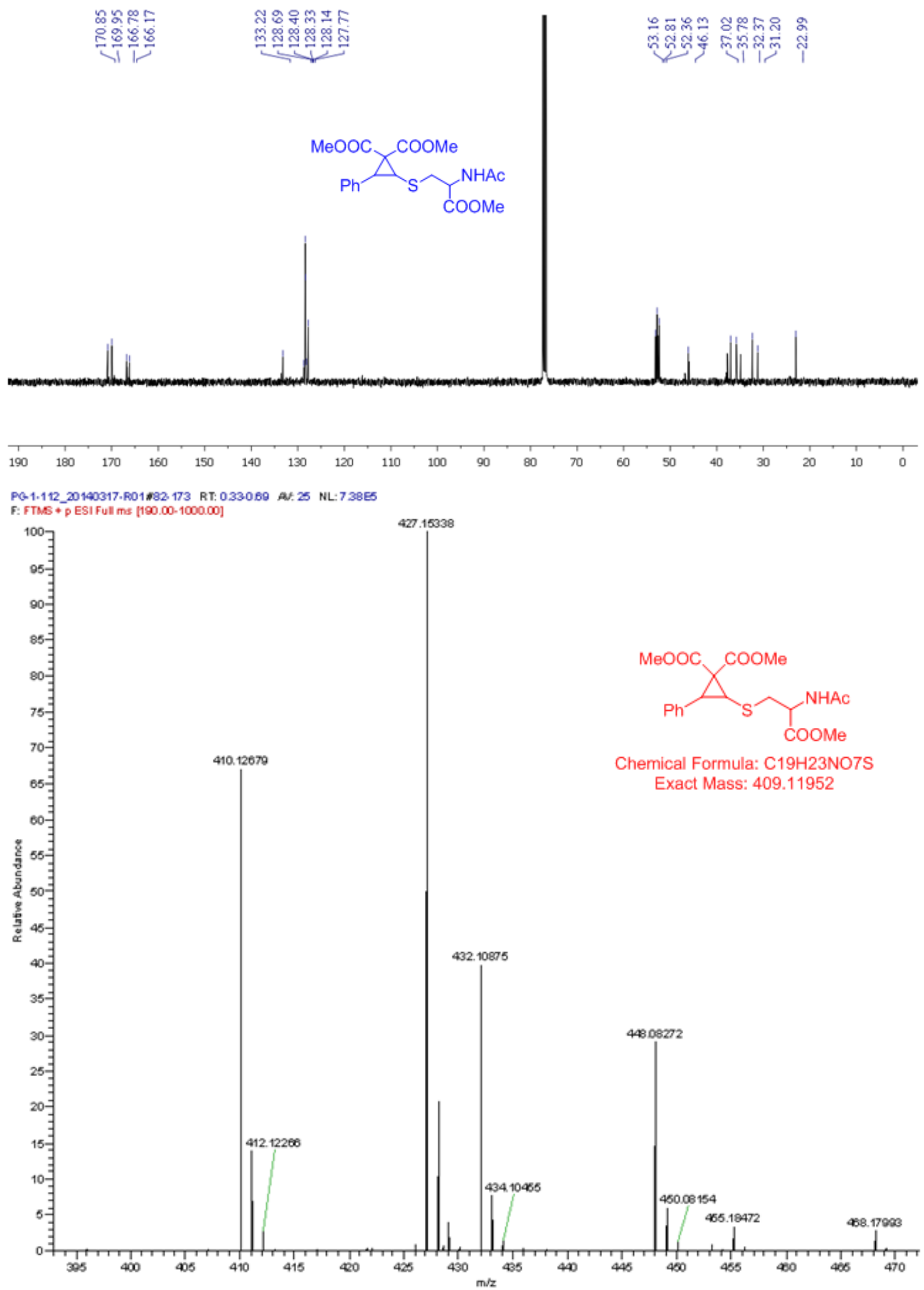


\section{REFERENCES}

[1] Goll, D. E.; Thompson, V. F.; Li, H.; Wei, W.; Cong, J., The Calpain System. Physiolol. Rev.2003, 83, 731-801.

[2] Dodds, R. A.; Connor, J. R.; Drake, F. H.; Gowen, M., Expression of cathepsin K messenger RNA in giant cells and their precursors in human osteoarthritic synovial tissues. Arthritis Rheum. 1999, 42, 1588-1593.

[3] Bervar, A.; Zajc, I.; Sever, N.; Katunuma, N.; Sloane, B. F.; Lah, T. T., Invasiveness of Transformed Human Breast Epithelial Cell Lines Is Related to Cathepsin B and Inhibited by Cysteine Proteinase Inhibitors. Biol. Chem. 2003, 384, 447-455.

[4] Kim, J. C.; Spence, R. A.; Currier, P. F.; Lu, X.; Denison, M. R., Coronavirus Protein Processing and RNA Synthesis Is Inhibited by the Cysteine Proteinase Inhibitor E64d. Virology 1995, 208, 1-8

[5] Rosenthal, P. J.; Sijwali, P. S.; Singh, A.; Shenai, B. R., Cysteine Proteases of Malaria Parasites: Targets for Chemotherapy. Curr. Pharm. Design 2002, 8, 1659-1672.

[6] Kathman, S. G.; Xu, Z.; Statsyuk, A. V., A Fragment-Based Method to Discover Irreversible Covalent Inhibitors of Cysteine Proteases. J. Med. Chem. 2014, 57, 4969-4974.

[7] Torkar, A.; Lenarčič, B.; Lah, T.; Dive, V.; Devel, L., Identification of new peptide amides as selective cathepsin L inhibitors: The first step towards selective irreversible inhibitors? Bioorg. Med. Chem. Lett. 2013, 23, 2968-2973.

[8] Parkes, C.; Kembhavi, A. A.; Barrett, A. J., Calpain inhibition by peptide epoxides. Biochem. J. 1985, 230, 509-516.

[9] Schirmeister, T., New Peptidic Cysteine Protease Inhibitors Derived from the Electrophilic $\alpha$-Amino Acid Aziridine-2,3-dicarboxylic Acid. J. Med. Chem. 1999, 42, 560-572.

[10] (a) Vicik, R.; Busemann, M.; Baumann, K.; Schirmeister, T., Inhibitors of Cysteine Proteases. Curr. Top. Med. Chem. 2006, 6, 331-353; (b) Schiefer, I. T.; Tapadar, S.; Litosh, V.; Siklos, M.; Scism, R.; Wijewickrama, G. T.; Chandrasena, E. P.; Sinha, V.; Tavassoli, E.; Brunsteiner, M.; Fa', M.; Arancio, O.; Petukhov, P.; Thatcher, G. R. J., Design, Synthesis, and Optimization of Novel Epoxide Incorporating Peptidomimetics as Selective Calpain Inhibitors. J. Med. Chem. 2013, 56, 6054-6068.

[11] (a) Li, X.; Chen, H.; Jeong, J.-J.; Chishti, A. H., BDA-410: A novel synthetic calpain inhibitor active against blood stage malaria. Mol. Biochem. Parasitol. 2007, 155, 26-32; (b) Ando, R.; Sakaki, T.; Morinaka, Y.; Takahashi, C.; Tamao, Y.; Yoshii, N.; Katayama, S.; Saito, K.-i.; Tokuyama, H.; Isaka,
M.; Nakamura, E., Cyclopropenone-containing cysteine proteinase inhibitors. Synthesis and enzyme inhibitory activities. Bioorg. Med. Chem. 1999, 7, 571-579.

[12] Quintana, J.; Barrot, M.; Fabrias, G.; Camps, F., A model study on the mechanism of inhibition of fatty acyl desaturases by cyclopropene fatty acids. Tetrahedron 1998, 54, 10187-10198.

[13] Billups, W. E.; McCord, D. J., Gas-Phase Synthesis of Reactive Molecules Using Adsorbed Reagents. Angew. Chem. Int. Ed. 1994, 33, 1332-1343.

[14] (a) Protopopova, M. N.; Doyle, M. P.; Mueller, P.; Ene, D., High enantioselectivity for intermolecular cyclopropenation of alkynes by diazo esters catalyzed by chiral dirhodium(II) carboxamides. J. Am. Chem. Soc. 1992, 114, 2755-2757; (b) Marek, I.; Simaan, S.; Masarwa, A., Enantiomerically Enriched Cyclopropene Derivatives: Versatile Building Blocks in Asymmetric Synthesis. Angew. Chem. Int. Ed. 2007, 46, 7364-7376; (c) Davies, H. M. L.; Lee, G. H., Dirhodium(II) Tetra(N-(dodecylbenzenesulfonyl)prolinate) Catalyzed Enantioselective Cyclopropenation of Alkynes. Org. Lett. 2004, 6, 1233-1236.

[15] Huang, D.; Koren, P. R.; Folting, K.; Davidson, E. R.; Caulton, K. G., Facile and Reversible Cleavage of C-F Bonds. Contrasting Thermodynamic Selectivity for RuCF2H vs FOsCFH. J. Am. Chem. Soc. 2000, 122, 8916-8931.

[16] Wang, F.; Luo, T.; Hu, J.; Wang, Y.; Krishnan, H. S.; Jog, P. V.; Ganesh, S. K.; Prakash, G. K. S.; Olah, G. A., Synthesis of gem-Difluorinated Cyclopropanes and Cyclopropenes: Trifluoromethyltrimethylsilane as a Difluorocarbene Source. Angew. Chem. Int. Ed. 2011, 50, 7153-7157.

[17] Chuprakov, S.; Malyshev, D. A.; Trofimov, A.; Gevorgyan, V., Sila Morita-Baylis-Hillman Reaction of Cyclopropenes. J. Am. Chem. Soc. 2007, 129, 14868-14869.

[18] De Simone, F.; Saget, T.; Benfatti, F.; Almeida, S.; Waser, J., Formal Homo-Nazarov and Other Cyclization Reactions of Activated Cyclopropanes. Chem. Eur. J. 2011, 17, 14527-14538.

[19] Roßbach, J.; Baumeister, J.; Harms, K.; Koert, U., Regio- and Diastereoselective Crotylboration of vic-Tricarbonyl Compounds. Eur. J. Org. Chem. 2013, 662-665.

[20] Liao, L.-a.; Zhang, F.; Yan, N.; Golen, J. A.; Fox, J. M., An efficient and general method for resolving cyclopropene carboxylic acids. Tetrahedron 2004, 60, 1803-1816.

[21] Zhang, F.; Fox, J. M., Synthesis of Cyclopropene $\alpha$-Amino Acids via Enantioselective Desymmetrization. Org. Lett. 2006, 8, 2965-2968.

[22] Griffith, A. K.; Vanos, C. M.; Lambert, T. H., Organocatalytic Carbonyl-Olefin Metathesis. J. Am. Chem. Soc. 2012, 134, 18581-18584. 